\title{
Fire design proposal for cold-formed steel lipped channel beam-columns
}

\author{
F. Arrais, N. Lopes \& P. Vila Real \\ RISCO, Department of Civil Engineering, University of Aveiro, Aveiro, Portugal
}

\begin{abstract}
Steel structural elements composed of cold-formed thin-walled sections are commonly applied in buildings due to their efficiency in terms of stiffness and strength. However, under fire conditions the thin walls of these profiles, along with the steel high thermal conductivity, induce fast increase on the steel temperature and corresponded significant loss of those referred stiffness and strength. This paper presents a numerical study on the members behaviour with cold-formed lipped channel sections at high temperatures, when subjected to bending plus compression. Comparisons between the finite element results and the analytical methodologies from EN1993-1-2 are presented, using its Annex E as well as its French National Annex, where different reduction factors for the steel constitutive law and different design formulae are recommended for cold-formed profiles. Both methodologies revealed to be safe but sometimes too conservative, which motivated the development of a new design proposal.
\end{abstract}

\section{INTRODUCTION}

Cold-formed steel profiles application on structures has been gaining popularity in construction industry due to their lightness, high strength-weight ratio, faster manufacturing process, easy prefabrication and mass production, contributing positively to the sustainability of buildings. These elements are typically used in steel structures as joists, tracks, studs or girts, subjected to different loading conditions (Schafer, 2011, Dubina et al., 2012).

Open cold-formed steel members have high susceptibility to the occurrence of different instability phenomena, such as local, global and also distortional buckling. The influence of these instability phenomena on the ultimate bearing capacity of beam-columns, composed of those cold-formed sections, at normal temperature have been widely studied (Torabian et al., 2015, Li et al., 2016). However, and although it is known that elevated temperatures impose significant loss of strength and stiffness on cold formed members (Kankanamge \& Mahendran, 2011, Ranawaka \& Mahendran, 2009), the behaviour under fire situation of these structural elements, subjected to bending plus compression, is still less known.

Hence, this paper presents a numerical parametric study on the behaviour of laterally restrained double hinged members with cold-formed lipped channel sections in case of fire, subjected to bending plus compression, considering different member and section slendernesses, bending moment diagrams, steel grades and elevated temperatures.

The members ultimate bearing capacity is obtained through numerical modelling, considering geometrically and materially nonlinear analyses including imperfections (GMNIA), using the Finite Element software SAFIR (Gernay \& Franssen, 2017). The different instability modes (local, distortional and global buckling), needed for the definition of initial geometric imperfections, are obtained using the software CAST3M (CAST3M, 2012) and applying RUBY interface (Couto et al., 2013).

DOI: $10.1201 / 9781003132134-62$ 
Comparisons between the finite element results and the analytical methodologies from EN1993-1-2 (CEN, 2005) rules are here presented, using its Annex E for Class 4 crosssections and its French National Annex (CEN, 2007), where different reduction factors for the steel constitutive law and different design formulae are recommended for coldformed profiles. Following the obtained observations, a new proposal for the safety evaluation of these cold-formed beam-columns at elevated temperatures is presented and analysed here.

\section{FIRE DESIGN RULES}

The EN1993-1-2 recommends the use of the 0,2\% proof strength at temperature $\theta$ instead of the strength at $2 \%$ total strain at temperature $\theta$, applied to non-slender sections (Class 1,2 or 3 ), for members with Class 4 cross-sections (common on cold-formed steel profiles).

The expression for laterally restrained steel beam-columns subjected to bending about the major axis in fire situation considered here is:

$$
\frac{N_{f i, E d}}{\chi_{y, f i} A_{e f f} k_{y, \theta} \frac{f_{y}}{\gamma_{M, f i}}}+k_{y} \frac{M_{y, f i, E d}}{W_{e f f, y} k_{y, \theta} \frac{f_{y}}{\gamma_{M, f i}}}+k_{z} \frac{\Delta M_{z, f i, E d}}{W_{e f f, z} k_{y, \theta} \frac{f_{y}}{\gamma_{M, f i}}} \leq 1.0
$$

with $A_{\text {eff }}$ (effective area) and $W_{\text {eff }, y}$ (effective section modulus) the cross-section effective properties, $\Delta M_{z, f i, E d}$ the additional bending moment due to the shift of the centroidal axis, and where the reduction factor $\chi_{f i}$ value is obtained according to equation (2):

$$
\chi_{f i}=\frac{1}{\phi_{\theta}+\sqrt{\left[\phi_{\theta}\right]^{2}-\left[\bar{\lambda}_{\theta}\right]^{2}}} \leq 1.0
$$

with:

$$
\phi_{\theta}=\frac{1}{2}\left[1+\alpha \bar{\lambda}_{\theta}+\left(\bar{\lambda}_{\theta}\right)^{2}\right]
$$

and $\alpha$ an imperfection factor determined by:

$$
\alpha=0.65 \sqrt{\frac{235}{f_{y}}}
$$

The recommended interaction factor, for Class 4 cross-sections, is obtained from:

$$
k_{i}=1-\frac{\mu_{i} N_{f i, E d}}{\chi_{i, f i} A_{e f f} k_{0.2 p, \theta} f_{y} / \gamma_{M, f i}} \leq 3 \text { with } i=y \text { or } z
$$

being $\mu$ (for the strong axis) given by:

$$
\begin{gathered}
\mu_{y}=\left(2 \beta_{M, y}-5\right) \bar{\lambda}_{y, \theta}+0.44 \beta_{M, y}+0.29 \leq 0.8 \text { with } \bar{\lambda}_{y, 20{ }^{\circ} \mathrm{C}} \leq 1.1 \\
\mu_{z}=\left(1.2 \beta_{M, z}-3\right) \bar{\lambda}_{z, \theta}+0.71 \beta_{M, z}-0.29 \leq 0.8
\end{gathered}
$$

and $\beta_{M, i}$, which is in function of the bending diagram shape, equal to: 


$$
\beta_{M, i}=1.8-0.7 \psi
$$

where $\psi$ is the ratio between the end moments ( $\left.\begin{array}{lll}1 & \psi & 1\end{array}\right)$.

The French National Annex (FN Annex) of EN1993-1-2 proposes a similar calculation methodology, considering for cold-formed steel profiles $k_{i}=1$ and lower reduction factors for steel yield strength and young modulus at high temperatures, when compared to Annex E of EN1993-1-2 (Zhao et al., 2005). Moreover, for flexural buckling the following equation should be used:

$$
\phi_{\theta}=\frac{1}{2}\left[1+\alpha\left(\bar{\lambda}_{\theta}-0.2\right)+\left(\bar{\lambda}_{\theta}\right)^{2}\right]
$$

considering the imperfection factor $\alpha$ obtained from EN1993-1-3 (CEN, 2006a), where curve $\mathrm{b}(\alpha=0.34)$ is proposed for lipped channel sections, and $\bar{\lambda}_{\theta}$ the relative slenderness for flexural buckling at the steel temperature $\theta$. A new proposal is presented here based in an adaptation methodology for flexural buckling on cold-formed steel lipped channel cross-section elements, proposed in previous studies (Arrais, 2018), where the equations considered in this new proposal remain the same from EN1993-1-2 considering the use of interaction equation (1) with the flexural buckling curve of FN Annex (equation 9) and a new limit for equation (6) of $\mu_{y} \quad 1.1$.

\section{CASE STUDY AND NUMERICAL MODELS}

The cold-formed lipped channel sections (C) presented on Table 1 were chosen from different references for the numerical analysis of beam-columns without lateral torsional buckling (LTB). Parameters such as the steel grade (S280, S320, S355 and S460), member slenderness $(0.5 \mathrm{~m}, 1.5 \mathrm{~m}, 3.0 \mathrm{~m}, 4.0 \mathrm{~m}, 5.0 \mathrm{~m}$ and $10.0 \mathrm{~m})$ and bending diagrams (uniform bending, $\psi=1$, and non-uniform bending $\psi=0$ and $\psi=-1$ ) are studied here. The temperatures of $350{ }^{\circ} \mathrm{C}$, $500{ }^{\circ} \mathrm{C}$ and $600{ }^{\circ} \mathrm{C}$ were applied and considered uniform throughout the cross section.

In the finite element model (Figure 1), rectangular shell finite elements with four nodes, with six degrees of freedom (three translations and three rotations), of $10 \mathrm{~mm}$ length over the member cross-section at flat plates, are used. The mesh was refined at the corners in order to better reproduce the rounded shape. In the longitudinal direction, the mesh size varies between $10 \mathrm{~mm}$ (for small lengths) and $25 \mathrm{~mm}$ (for the longest member). For imposing end moments, loads in the parallel direction to the beam-column axis were applied on the nodes at the element ends, according to the linear stresses distribution resulting from simple bending around the strong axis. Restrictions are applied to reproduce simple supports on beam-column ends.

This study did not take into account the corner enhancement, resulting from the manufacturing process, since this increase is not considered in EC3 (CEN, 2006a) in the occurrence of instability phenomena and because its influence is reduced at high temperatures (Arrais et al. 2019). Residual stresses were considered according to Schafer \& Peköz (1998).

\begin{tabular}{|c|c|c|c|c|}
\hline & Web & Flange & Lip & Thickness \\
\hline Designation & $\mathrm{mm}$ & $\mathrm{mm}$ & $\mathrm{mm}$ & $\mathrm{mm}$ \\
\hline C_229x64x20x(1.5)* & 229 & 64 & 20 & 1.5 \\
\hline C_ $154 \times 35 \times 11 \times(1.5)^{* *}$ & 154 & 35 & 11 & 1.5 \\
\hline C_- $150 \times 43 \times 20 \times(2.0)^{* * *}$ & 150 & 43 & 20 & 2.0 \\
\hline
\end{tabular}

Table 1. Lipped channel sections analysed and respective dimensions. 


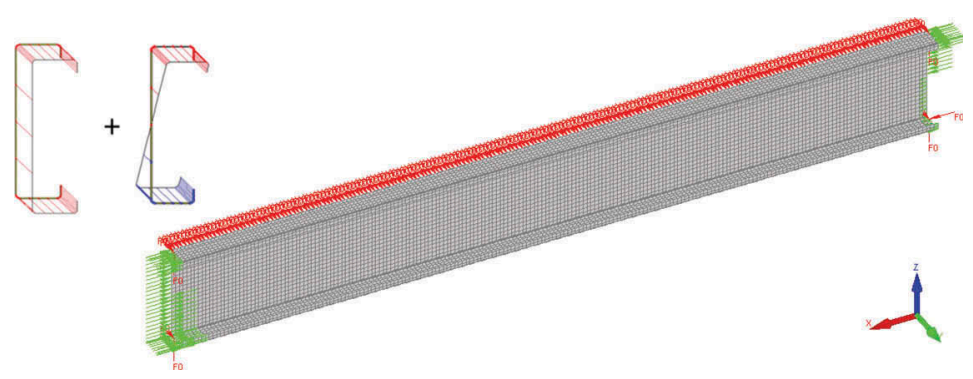

Figure 1. Numerical model adopted for analysed beam-columns.

Table 2. Geometric imperfections' magnitudes considered.

\begin{tabular}{lll}
\hline Local & Distortional & Global \\
\hline $0.80 \frac{b}{100}$ & $0.80 \frac{b}{100}$ & $0.80 \frac{L}{750}$ \\
\hline
\end{tabular}

The shapes obtained from local, distortion and global buckling modes, applying CAST3M program together with the RUBY interface, were used to define the initial geometric imperfections. According to Annex C of EN 1993-1-5 (CEN, 2006b), the geometric imperfections' magnitudes were obtained from $80 \%$ of the geometric manufacturing tolerances prescribed in EN 1090-4 (CEN, 2018). Table 2 shows the maximum amplitude of these imperfections where $b$ is the length of the web or flange, depending on the highest deformation value, and $L$ is the member length.

A geometric imperfection's combination is introduced in the numerical model. EN 19931-5 states that a leading imperfection should be chosen, and the accompanying imperfections may have their value reduced to $70 \%$. In this work, the leading imperfection was chosen according to the achieved lower resistances from each individual imperfection obtained resistance.

The applied steel material laws follow EN 1993-1-2 steel constitutive law model. However, and as aforementioned, FN Annex proposes for cold-formed profiles the use of lower values for the reduction factors of the yield strength and elasticity modulus at elevated temperatures. The comparison between the EN 1993-1-2 and FN Annex constitutive laws is presented in Figure 2.

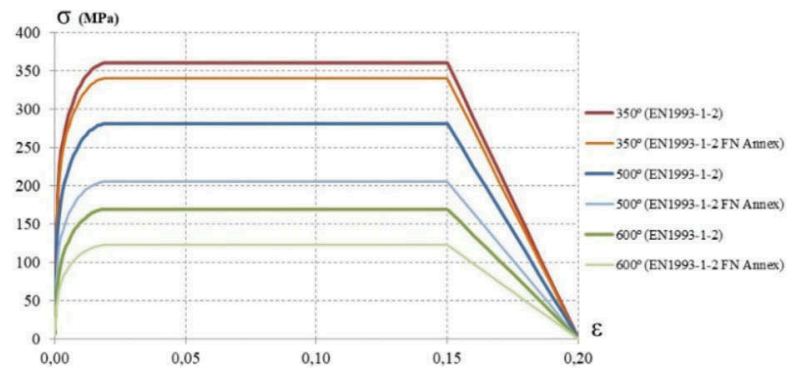

Figure 2. Constitutive law for elevated temperatures according to EN1993-1-2 and respective FN Annex. 


\section{COMPARISON BETWEEN NUMERICAL RESULTS AND FIRE DESIGN RULES}

The numerically obtained ultimate bearing load capacities are here compared with the calculation rules of EN 1993-1-2. Since the analysed profile is composed of a monosymmetric section, the change of the centre of gravity, due to the consideration of the effective area $A_{\text {eff }}$, results in an eccentricity of the applied axial force, which induces an additional, $\Delta M_{\mathrm{z}, \mathrm{fi} \text {.Ed }}$, acting bending moment about the weak axis. For illustrating the referred comparisons for a $\mathrm{C} 229 \times 64 \times 20$ with $1.5 \mathrm{~m}$ length at $500{ }^{\circ} \mathrm{C}$ with different load levels, this additional moment was added to the axial force buckling resistant capacity on the vertical axis of the charts in Figures 3 (uniform bending) and 4 (triangular bending diagram). Figure 5 illustrates the failure mode of tested beam-columns.
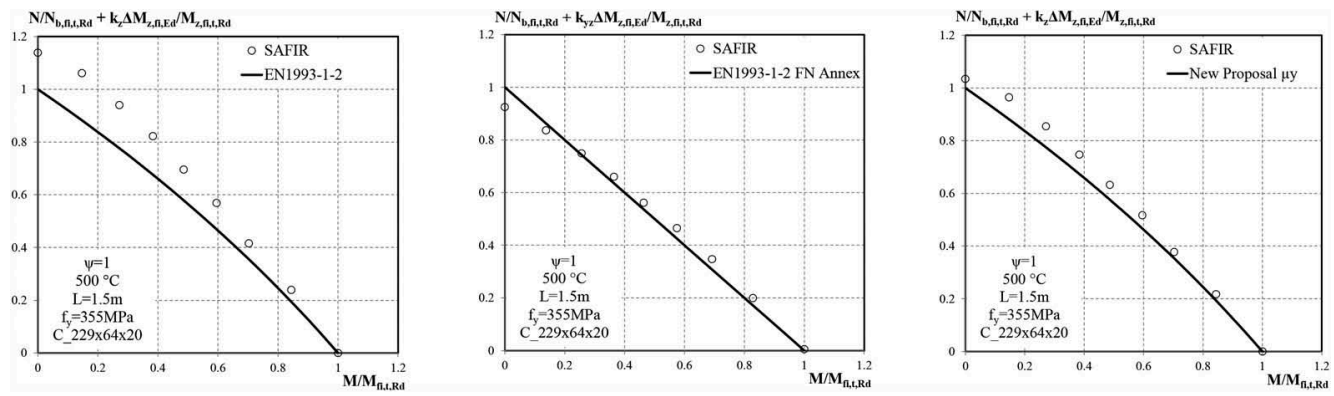

Figure 3. Comparison between the numerical results and the design rules of the EN1993-1-2 Annex E, the French National Annex (FNA) and the New Proposal, for uniform bending $(\psi=1)$, at $500^{\circ} \mathrm{C}$.
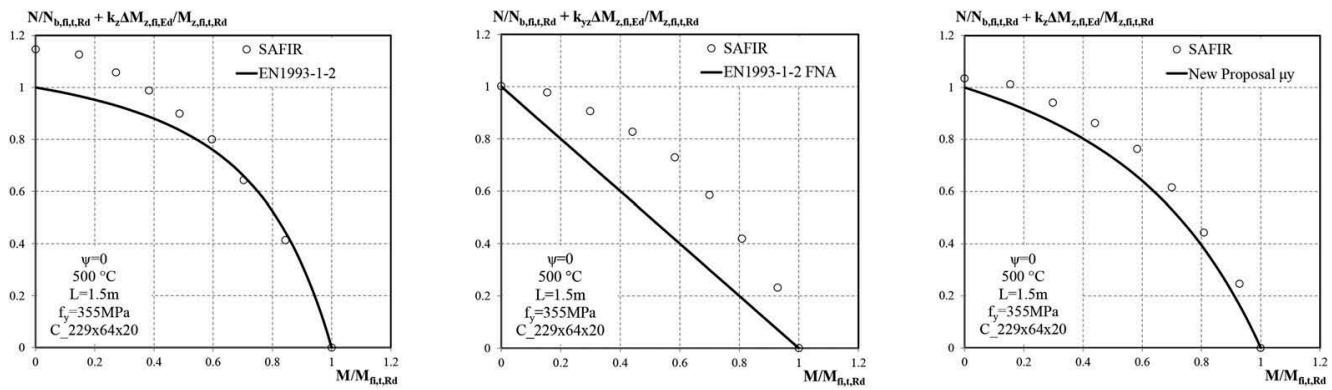

Figure 4. Comparison between the numerical results and the design rules of the EN1993-1-2 Annex E, the French National Annex (FNA) and the New Proposal, for non-uniform bending $(\psi=0)$, at $500{ }^{\circ} \mathrm{C}$.

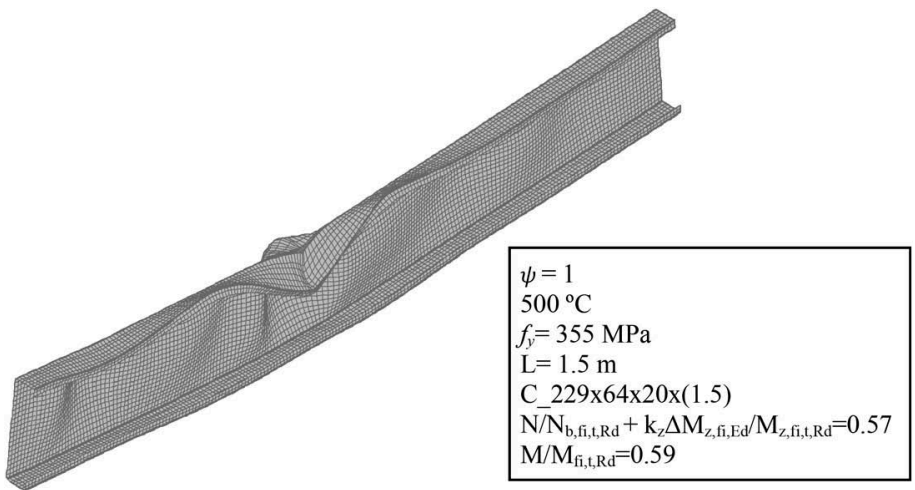

Figure 5. Collapse mode of a C_229x64x20 section beam-column model. 
Table 3. Statistical evaluation considering uniform bending diagram on a total of 1176 results.

\begin{tabular}{llllc}
\hline Design rule & Average value $(\mu)$ & Standard deviation $(s)$ & Máx. unsafe & $\%$ unsafe \\
\hline $\begin{array}{l}\text { EN1993-1-2 } \\
\text { (EN1993-1-2 Constitutive Law) }\end{array}$ & 0.93 & 0.10 & - & 0.00 \\
$\begin{array}{l}\text { EN1993-1-2 FNA } \\
\text { (FN Annex Constitutive Law) }\end{array}$ & 1.09 & 0.16 & 1.05 & 18.23 \\
$\begin{array}{l}\text { New Proposal } \\
\text { (FN Annex Constitutive Law) }\end{array}$ & 0.97 & 0.03 & 1.02 & 6.74 \\
\hline
\end{tabular}

Table 4. Statistical evaluation considering non-uniform bending diagram results on a total of 1512 results.

\begin{tabular}{llllc}
\hline Design rule & Average value $(\mu)$ & Standard deviation $(s)$ & Máx. unsafe & $\%$ unsafe \\
\hline $\begin{array}{l}\text { EN1993-1-2 } \\
\text { (EN1993-1-2 Constitutive Law) }\end{array}$ & 0.67 & 0.30 & - & 0.00 \\
$\begin{array}{l}\text { EN1993-1-2 FNA } \\
\text { (FN Annex Constitutive Law) }\end{array}$ & 1.31 & 0.33 & 1.07 & 12.37 \\
$\begin{array}{l}\text { New Proposal } \\
\text { (FN Annex Constitutive Law) }\end{array}$ & 0.81 & 0.28 & 1.01 & 6.51 \\
\hline
\end{tabular}

Following the criteria of the validation proposed by Kruppa (1999), Table 3 presents the statistical evaluation for uniform bending moments based on a total of 1176 results (considering both constitutive laws) and Table 4 for non-uniform bending moments based on a total of 1512 results.

From the presented comparisons, it can be concluded that both approaches are mostly on the safety side, being however too conservative. Considering FN Annex, the values are closer to the EC3 curve for $\psi=-1$, whereas in the case of non-uniform moments, the curve remains very conservative, as in this methodology the interaction factor $\boldsymbol{k}_{\boldsymbol{y}}$ and $\boldsymbol{k}_{z}$ are always one. The proposed adjustments are more accurate and safe when compared to the numerical results.

\section{CONCLUSIONS}

In the present work, a parametric study of the fire behaviour of cold-formed beam-columns with lipped channel (C) sections, without lateral torsional buckling, was presented, considering the EN1993-1-2 as well as its French National Annex constitutive laws.

A comparison was made between the ultimate load capacities obtained numerically and the requirements of EC3, concluding that these last calculation rules are on the safety side in most cases, being too conservative. The comparison with the FN Annex demonstrated that the values are closer to the FNA curve, whereas in the case of non-uniform moments, the curve remains very conservative. The results were obtained considering the variation of several parameters such as different steel grades, bending moment diagrams and slendernesses.

Thus, a new design proposal was developed with some adjustments in relation to the current calculation rules. It was possible to observe that the new proposal presents a better approximation to the numerical results when compared to EC3.

\section{ACKNOWLEDGEMENTS}

This research was partially funded by the Portuguese Government through the FCT (Foundation for Science and Technology) under the PhD grant SFRH/BD/90455/2012 (POPH/FSE 
funding) awarded to the first author and was performed within the framework of the project "StaSteFi - Fire design of stainless steel members", PTDC/ECI-EGC/30655/2017, supported by the Portuguese Operational Programme "Competitividade e Internacionalização", in its FEDER/FNR component, and the Portuguese FCT, in its State Budget component (OE).

\section{REFERENCES}

Arrais, F., Behaviour of cold-formed steel members in case of fire, $\mathrm{PhD}$ thesis, University of Aveiro, Portugal, 2018.

Arrais, F., Lopes, N., Vila Real, P., Jandera, M., Numerical modelling of cold-formed steel members at elevated temperatures, proceedings of SDSS 2019, Prague, Czech Republic, 2019.

CAST3M, sponsored by French Atomic Energy Commission; 2012. http://www-cast3m.cea.fr/

CEN - EN 1993-1-2, Eurocode 3: Design of Steel Structures - Part 1-2: General rules - Structural fire design, Belgium, 2005.

CEN - EN 1993-1-3, Eurocode 3: Design of Steel Structures - Part 1-3: Rules for cold-formed members and sheeting, Belgium, 2006a.

CEN - EN 1993-1-5, Eurocode 3: Design of Steel Structures - Part 1-5: Plated structural elements, Belgium, 2006b.

CEN - EN 1090-4, Execution of steel structures and aluminium structures - Part 4: Technical requirements for cold-formed structural steel elements and cold-formed structures for roof, ceiling, floor and wall applications, Belgium, 2018.

CEN - NF EN 1993-1-2, Eurocode 3: Calcul des structures en acier - Annexe Nationale à la NF EN 1993-1-2: Calcul du comportment au feu, Belgium, 2007.

Couto, C., Vila Real, P., Lopes, N., RUBY - an interface software for running a buckling analysis of SAFIR models using Cast3M, University of Aveiro, 2013.

Dubina, D., Ungureanu, V., Landolfo, R., Design of cold-formed steel structures, ECCS - European Convention for Constructional Steelwork, Ernst \& Sohn, 2012.

Gernay, T., Franssen, J.M. (2017), "Modeling structures in fire with SAFIR ®: Theoretical background and capabilities", Journal of Structural Fire Engineering, Vol. 8, issue 3, pp. 300-323.

Kankanamge, N. D., Mahendran, M., Mechanical properties of cold-formed steels at elevated temperatures, Thin-Walled Structures, Vol. 49, Iss 1, 2011, 26-44.

Kruppa, J. Eurocodes - fire parts, proposal for a methodology to check the accuracy of assessment methods, CEN TC 250, Horizontal Group Fire, Document n 99/130, 1999.

Li, Y.-L., Li, Y.-Q., Song, Y.-Y., Shen, Z.-Y, In-plane behavior of cold-formed thin-walled beam-columns with lipped channel section, Thin-Walled Structures, Vol. 105, pp. 1-15, 2016.

PERFISA - Steel Profiles Factory, S.A., Catalogue: Profiles for Light Steel Framing, Portugal, 2014.

Ranawaka, T., Mahendran, M., Experimental study of the mechanical properties of light gauge cold-formed steels at elevated temperatures, Fire Safety Journal, Vol. 44, Iss 2, 2009, 219-229.

Schafer, B., Cold-formed steel structures around the world. Steel Construct., 4, 2011, 141-149.

Schafer, B., Peköz, T., Computational modeling of cold-formed steel: characterizing geometric imperfections and residual stresses, J. of Constructional Steel Research, 47, 3, 1998, 193-210.

Torabian, S., Zheng, B., Schafer, B. W. "Experimental response of cold-formed steel lipped channel beam-columns", Thin-Walled Structures, Vol. 89, pp. 152-168, 2015.

Zhao B., Kruppa J., Renaud C., O'Connor M., Mecozzi E., Apiazu W., Demarco T., Karlstrom P., Jumppanen U., Kaitila O., Oksanen T., Salmi P., Calculation rules of lightweight steel sections in fire situations, European Commission, Luxembourg, 2005. 